\title{
Satisfaction and Risk Prevention of the Public-Private Partnership- An Empirical Analysis Based on the Case of Xingtai, Hebei
}

\author{
Yang Tuo $^{1}$ Lu Ning $^{2}$ Shao Bang ${ }^{1}$ \\ ${ }^{1}$ School of Public Administration, Beihang University, Beijing, P.R.China, 100191; \\ ${ }^{2}$ Development Research Center, Yunnan University of Finance and Economics, Kunming, P.R.China, \\ 650221 \\ (E-mail:yangtuo@126.com, luning5112805@163.com,chobard@126.com)
}

\begin{abstract}
Public-private partnerships refers to playing comparative advantages and raising the level of supply of public goods and services between the public sector and the private sector through profit sharing, risk-sharing, and collaborative participation. through analysis on causal connections between the indicators changes and overall satisfaction degrees of public-private partners relationship, the article uses main components factor analysis to summarize five dimension degrees of indicators, including economic, risk, environment, regulatory, and participation. And builds out public-private partners relationship satisfaction degrees structure model based on the digits, calculating out the dimension degrees and overall satisfaction degrees between of path coefficient and concluding that risk dimension degrees is an important indicators dimension degrees effecting overall satisfaction degrees. The article further gives suggestions on perfecting risk share mechanism, establishing trust guarantees mechanism and building reward incentive mechanism.
\end{abstract}

Keywords: Satisfaction, Structural equation Model, Factor Analysis

\section{Introduction}

Public-private partnerships refer to partnerships between the public and private sectors, to achieve comparative superiority and improve the level of supply of public goods and services by sharing the proceeds, risk-sharing, and collaborative participation.[1] Under the public-private partnership, operation and management is responsible by the private sector. The private sector can not only play advantages in resource mobilization and management, but also significantly increase the operation efficiency, as a result of their internal incentive mechanism. Public sector can use its powers, such as policy development and urban planning to make system design and arrangement in market access, pricing mechanisms and regulation of public services and goods to guarantee the quality of the supply of public goods and services. This balance between equity and efficiency can make public sector and the private sector to play their advantages, take risks, and share gains respectively, thereby ensuring the best use of funds. As an effective way to raise the level of public goods supply, public-private partnerships generated in the United Kingdom and quickly spread widely around the world, becoming an important component of innovation and reform.

However, Traditional public-private partnership focuses too much on the cooperation between government and enterprises, on the distribution of interests among public and private sectors, and lacks 
attention to the public, the thing has the deepest and largest influence on public goods and services, ignoring the level of satisfaction. Due to the fact that is cycle-long, construction-complex, and highly externalized, the effect range of public-private partnership cooperation project is more than limited within public sector and private sector. The public, being stakeholders, cannot participate in the construction of public-private partnerships, and with unclear benefit expression mechanism, their interests are difficult to guarantee. Therefore they have to use non-rational way to express their interests demands, resulting various and endless conflict events. Therefore, research on satisfactory degree of public-private partnerships has a very important theoretical and practical significance on enhancing the efficiency of the supply of public goods and services.

\section{Literature Review}

"Satisfaction" is the study of issues in the field of psychology.[2] Xu Liancang (1978), based on the development needs of the reform and economic construction, worked with colleagues about a report on employee job satisfaction survey, which published in the Guangming daily and caused extensive attention of public opinion. It is commented by Western as "pioneer of Chinese public opinion polls".[3] This is the first investigation of job satisfaction in china, and since then related researches on job satisfaction gradually become popular in China. Liu Fengyu, and Zhang Jincheng (2004), through research on work satisfaction degrees of employees in private enterprises of Zhejiang and Guangdong, found senior management, training development, customer service and departement employees are in are four main factors effecting employees' work satisfaction degrees in private enterprise. And pay welfare and work target almost have no effect on employees' work satisfaction degrees, breaking the General believes that pay welfare is the led factor effecting employees work satisfaction degrees.[4] based on investigation analysis of government performance evaluation in China and existing issues, $\mathrm{Xu}$ Youhao (2004) has made customer satisfaction index model method of evaluating the performance of the Government, and an evaluation method based on customer satisfaction: an empirical analysis of the performance of the Government.[5] You Jianxin (2004) proposed the use of analytic hierarchy process to the evaluation of public satisfaction, considering public satisfaction is the change of administration, innovation of methods and the Government should attach great importance to this concept and method.[6] Chen Zengming (2007) believes that due to nature complex of the Government by engaged in of public service, social public satisfaction degrees evaluation elements constitute is relative more complex than general significance of customers satisfaction degrees evaluation. However, public satisfaction degrees evaluation indicators and Government functions is closely related, therefore, based on four areas, administrative style and environment situation satisfaction degrees, economic development situation satisfaction degrees, government open satisfaction degrees, and benefit degree satisfaction degrees starting, Chen builds a three levels indicators system.[7] Some scholars also conducted studies of the relationship between sense of community belonging and residents satisfaction with the communities and residents.

Satisfaction models made by Scholars have, to some degree, explained the influence factor and formation process of satisfaction. These studies have made a positive contribution to the theroetical development of customer satisfaction, satisfaction, community residents satisfaction of public service. 
However, documents above mentioned have not contained in-depth discussion of the expansion of satisfaction of the public-private partnership, and rarely mentioned stakeholders of public-private partnerships, Governments, businesses, and the public. To this end, the author make public-private partnerships as the Center, based the point of satisfaction and on public-private partnerships of Government, business, public research in order to dig out reasons of public-private partnership satisfaction, thus improving the level of supply of public goods and services.

\section{Research Design}

Research Group, through field surveys in Xingtai city and quantitative analysis, dig out public-private partnership satisfaction reasons. Research process is described below:

Defined under public-private partnership concept, combined with the service expectations of the public-private partnership, the research target will be divided into three levels of evaluation index system. The satisfaction of the public-private partnership is the first-level indicators, with chosen benefits, risks, and participation are second-level indicators, and it further expanded to 24 three-level indicators. Collected through pilot scale analysis, $10 \%$ scored the highest and $10 \%$ lowest scores investigated are subtracted to gain resolution coefficient in each indicator. High point refers to a high-resolution coefficient of representation, and low point should be deleted due to their lack of representation. 4 indicators in questionnaire are low-resolution coefficients and are deleted. Ultimately, 20 indicators are selected as the index of satisfaction of public-private partnerships.
Study on the satisfaction of the public-private partnership involves the government, public and enterprises. To ensure the accuracy of the sampling process and representation to avoid human interference, it is necessary to choose individuals according to their different characteristics, select a stratified sampling as a means of sampling, selecting Qiaoxi County, Linxi County, Weixian County, Guangzong County and, Nangong City, for satisfaction study. First stage in above five County (area) is the selection of 100 government official personnel samples; second stage is selecting 20 menagers of private sector, determines 100 private sector samples; third stage is random sampling 100 residents in the County (area) square. A total of 300 samples are selected.

\section{Statistical Analysis}

\subsection{Factor Extraction and Its Reliability Analysis}

The present Study uses Principal Component Analysis as Extraction Method. The calculated value of KMO 0.770, Bartlett approximate chi-square values are 2461.11, p $=0.000<$ 0.05 significant probability values, data suitable for analysis. Further, Varimax rotation factor is used, factor of extracting characteristic value greater than 1 , revealed there are five common factors that the eigenvalues greater than 1 . Five factors of total variance explained rate of $77.477 \%$. So we believe this five factors are able to explain most of the original data information with good representation. 


\begin{tabular}{ccccccccccc}
\hline \multirow{2}{*}{ Component } & \multicolumn{3}{c}{ Initial eigenvalue } & \multicolumn{3}{c}{$\begin{array}{c}\text { Extraction sum of squared } \\
\text { loadings }\end{array}$} & \multicolumn{3}{c}{ Rotation sums of squared } \\
\cline { 2 - 10 } & $\mathrm{E}$ & $\mathrm{VC}$ & $\mathrm{CVC}$ & $\mathrm{E}$ & $\mathrm{VC}$ & $\mathrm{CVC}$ & $\mathrm{E}$ & $\mathrm{VC}$ & $\mathrm{CVC}$ \\
\hline 1 & 5.447 & 32.234 & 32.234 & 5.447 & 32.234 & 32.234 & 3.289 & 21.446 & 21.446 \\
2 & 2.234 & 15.169 & 47.403 & 2.234 & 15.169 & 47.403 & 2.681 & 17.406 & 38.852 \\
3 & 1.875 & 12.375 & 59.778 & 1.875 & 12.375 & 59.778 & 2.375 & 14.876 & 53.728 \\
4 & 1.580 & 9.901 & 69.679 & 1.580 & 9.901 & 69.679 & 2.114 & 12.571 & 66.299 \\
5 & 1.360 & 7.798 & 77.477 & 1.360 & 7.798 & 77.477 & 2.036 & 11.178 & 77.477 \\
\hline
\end{tabular}

Extraction Method: Principal Component Analysis.

\section{Table 1 Variance Explained (\%)}

By observing the rotated matrix of factors, five factors are named: Q1-Q4 induction is named "economic dimensions"; Q5-Q8 induction is named "risk dimension"; Q9-Q12 induction is named "environmental dimension"; Q13-Q16 induction is named "regulatory dimensions"; Q17-Q20 induction is named "involved in dimension". 0.851 factor Cronbach $\alpha$ coefficient values mentioned above, greater than 0.80 . Survey data with high internal consistency, reliability is good.

\subsection{Structural Equation Model}

Structural equation model is based on a theory, linear equation systems using the appropriate method of the theory of statistical analysis. It is used to indicate measurements between latent variables and variables as well as mutual relations between latent variables.

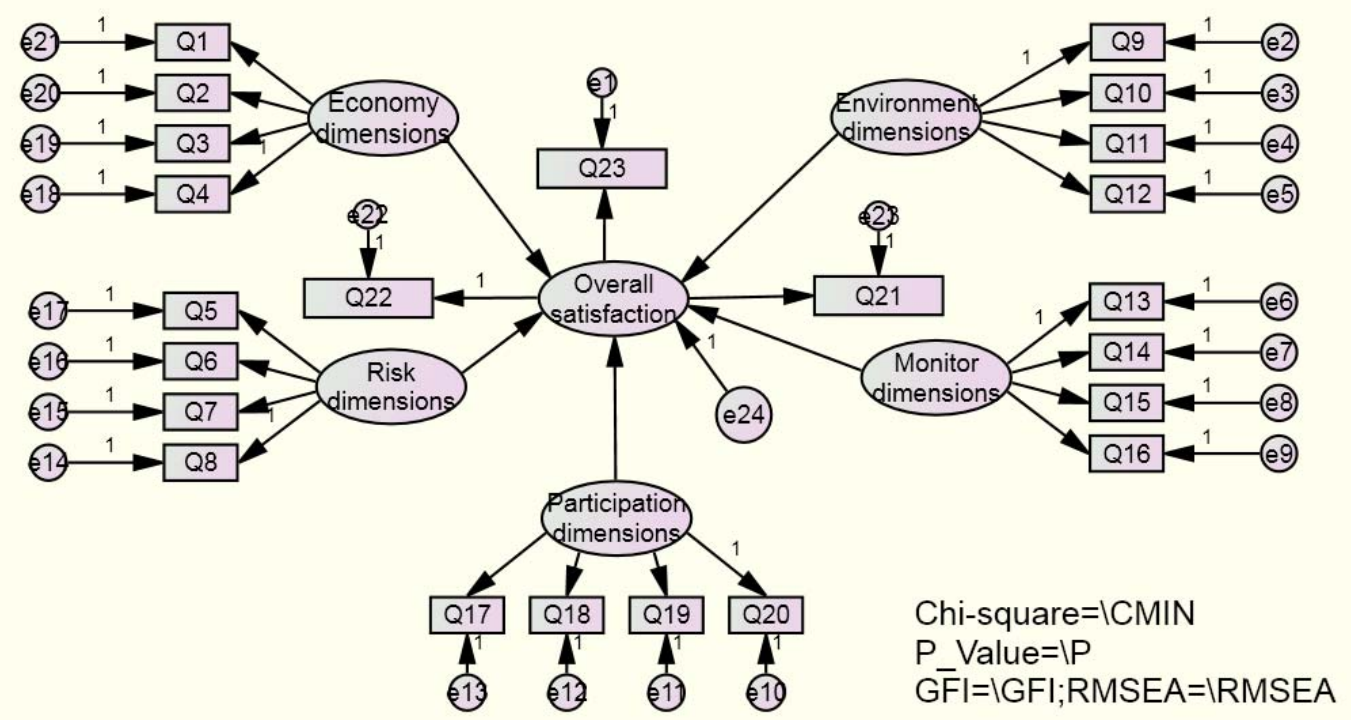

Figure 1 Structural Equation Model of Public-Private Partnership Satisfaction Road Map 
Extracts of five factors are using factor analysis construction structural equation model(SEM) of public-private partnerships for satisfaction. Economy dimension, Risk dimension, Environmental dimension, Monitor dimension and Participation dimension five aspects are used as external latent variables, with each latent variable questions as contained in its measurement variables, inherent latent variable overall satisfaction. Q21, Q22 and Q23, three questions in the questionnaire are used as a measure of overall satisfaction variables. Measurement model reflects the five overall satisfaction of the external measurement of latent variables with the corresponding measuring relationships between the variables. Structure model reflects relation between the latent variables and the overall satisfaction of five external structural, Economy dimension, Risk dimension, Environmental dimension, Monitor dimension and Participation dimension. With AMOS software build SEM of the road map, as shown in Figure 1.

\begin{tabular}{ccccccc}
\hline Model & CMIN & DF & CMIN/DF & P & GFI & RMSEA \\
Default & 552 & 225 & 2.45 & 0.56 & 0.907 & 0.01 \\
\hline
\end{tabular}

Table 2 Satisfaction of the Public-Private Partnership Structural Equation Model Fit

Model running results are shown in table 2. CMIN value is 552, Df is 225, and CMIN/df is 2.45. Significant levels of probability $P$ is $0.56>0.05$, GFI 0.907 $>0.9$, RMSEA $0.01<0.05$, structural equation model of public-private partnership satisfaction result fits better.

Tab 3 is structural equation modeling operations and concludes that five factors' influence on overall satisfaction levels of standardized path coefficients. $\mathrm{P}$ values have reached significant levels $(\mathrm{P}<0.05)$. Sorted by impact from strong to weak followed by Risk dimension (0.583) > Monitor dimension (0.460) $>$ Economy dimension (0.445) > Participation dimension (0.387) > Environmental dimension (0.201). Analysis results better reflected the overall satisfaction factors, satisfaction for public-private partnerships and enhance the provision of reliable quantitative basis.

\begin{tabular}{ccc}
\hline Regression & Standardized Regression & P \\
Weights & 0.445 & 0.00 \\
\hline Economy dimensions $\rightarrow$ Overall satisfaction & 0.583 & 0.00 \\
Risk dimensions $\rightarrow$ Overall satisfaction & 0.387 & 0.00 \\
Participation dimensions $\rightarrow$ Overall satisfaction & 0.460 & 0.00 \\
Monitor dimensions $\rightarrow$ Overall satisfaction & 0.201 & 0.01 \\
Environment dimensions $\rightarrow$ Overall satisfaction & & \\
\hline
\end{tabular}

Table 3 Latent Variable Path Coefficients and Significance Tests

Through the path of regression coefficients of the model of equation: $\mathrm{Y}=0.445 * X_{1}+0.583 * X_{2}+0.387 * X_{3}+0.460 * X_{4}$ $+0.201 * X_{5}$;
Note: $X_{1}, X_{2}, X_{3}, X_{4}, X_{5}$ represented Economy dimension, Risk dimension, Environmental dimension, Monitor dimension and Participation dimension.

When the Economy dimension, Risk 
dimension, Environmental dimension, Monitor dimension and Participation dimension raise 1 standard units, overall satisfaction increased $0.445,0.583,0.387,0.460$ and 0.201 standard units. Analysis showed that the risk dimension is the most important element.

\section{Conclusions}

The key to promoting the satisfaction of the public-private partnership is to improve the weaknesses in the tripartite satisfaction. As the Governments, businesses, the public have different emphasizes, policy formulation and implementation and different. Government on Economy dimension and Risk dimension, through public-private partnerships improved supply process, reduced cost, and upgrade efficiency, reflected public sector expectations and a inherent driven of pursuit social benefits. Enterprise concern risk and participation dimension of concern stems from the gradual deterioration of domestic investment environment, the international financial crisis and instability of local policy, the current some local government sector for pursuit achievements of needs, accelerated based facilities construction, is not on project for feasibility demonstration, nor taking into account the local economic development and financial paid level. Blind with private sector signed cooperation agreement for both brings great cooperation risk, private sector on risk of concern is on uncertainty of a prevention, expectations through participation public-private partnership project towards interests maximize; public on participation dimension and Monitor dimension of concern, stems from Monitor sector lack must of regulatory level, difficult to on private sector of management, production technology, and risk against capacity for accurate judgment, it cannot effective avoiding potential risk, resulted public crisis event frequency made, and Public interests are violated. So to raise the level of government regulation of public-private partnerships and to participate in the public-private partnership projects to their expressed concerns to influence policy development, it should be seen that improving satisfaction of the public-private partnership is a dynamic process. Due to the focus of concern are different among Government, businesses, and the public, the key to promoting the satisfaction of the public-private partnership is to improve the weaknesses in the tripartite satisfaction. Analysis shows that the risk dimension most noticeable impact on overall satisfaction, take corrective action, raising the level of risk, can improve the overall level of satisfaction.

\section{References}

[1] Yang tuo, Lu ning. Positioning and adjustment of the public-private partnership[J]. Economics and management, 2011, (12): 29-33. (In Chinese)

[2] Wang Xin. Study on customer satisfaction of cultivating talents in colleges [D]. Hebei Normal University, 2008.

[3] Huang Xianyong. Study on job satisfaction and its influencing factors [D]. Tianjin Normal University, 2008.

[4] Liu Fengyu, Zhang Jincheng. Effectiveness of employee's job satisfaction survey questionnaire and study on influence factors of private enterprise employee job satisfaction [J]. Nankai business review, 2004, (3): 100-106. (In Chinese)

[5] Xu Youhao, WU Yanbing. Application of customer satisfaction degree in the Government performance evaluation [J]. Journal of Tianjin University (Social Science Edition), 2004, (10): 325-328. (In Chinese)

[6] You Jianxin, Shao Luning, Yang Miao. The public satisfaction philosophy and public satisfaction evaluation [J]. Shanghai 
management science, 2004, (2): 58-60.

(In Chinese)

[7] Chen zengming. Community discussion on public satisfaction evaluation [J]. Journal of Fujian commercial college. 2007, (1): 30-33. (In Chinese) 